\title{
The Calpastatin-Derived Calpain Inhibitor CP1B Reduces mRNA Expression of Matrix Metalloproteinase-2 and -9 and Invasion by Leukemic THP-1 Cells
}

\author{
Oliver Popp, Michael Heidinger, Lourdes Ruiz- \\ Heinrich, Christian Ries, Marianne Jochum and \\ Shirley Gil-Parrado* \\ Abteilung für Klinische Chemie und Klinische \\ Biochemie, Chirurgische Klinik Innenstadt, Klinikum der \\ LMU München, Nussbaumstr. 20, D-80336 München, \\ Germany
}

*Corresponding author

The ubiquitous proteases $\mu$ - and $m$-calpain are $\mathrm{Ca}^{2+}$-dependent cysteine endopeptidases. Besides involvement in a variety of physio(patho)logical processes, recent studies suggest a pivotal role of calpains in differentiation of hematopoietic cells and tumor cell invasion. However, the precise actions of calpains and their endogenous inhibitor, calpastatin, in these processes are only partially understood. Here we have studied the role of the calpain/calpastatin system in the invasion of leukemic cells under basal and differentiation-stimulating conditions. To further differentiate the human leukaemic cell line THP-1 (monocytic), the cells were treated for $\mathbf{2 4}$ hours with the differentiation-stimulating reagents phorbol 12-myristate 13-acetate (PMA) and dimethyl sulfoxide (DMSO). Macrophage- and granulocyte-like differentiation was confirmed by induction of vimentin expression as well as by microscopic and fluorescence-assisted cytometric analysis. Extracellular matrix (ECM) invasion of both the basal and differentiation-stimulated cells in a Matrigel assay was inhibited by pre-incubation of the cells with the specific calpain inhibitor CP1B for 24 hours. Inhibition of invasiveness correlated with decreased mRNA expression and secretion of the matrix metalloproteinases MMP-2 and MMP-9. In contrast, addition of CP1B only during the invasion process did neither influence transmigration nor MMP release. This is the first report showing that the calpain/calpastatin system mediates MMP-mRNA expression of the leukemic THP-1 cells and as a consequence their invasiveness. Key words: Calpastatin/Differentiation/Inhibitor/ Protease/Tumor.
The ubiquitously expressed calpain/calpastatin system comprises the calpain isoforms, $\mu$-calpain $(\mu \mathrm{Cp})$ and $\mathrm{m}$ calpain $(\mathrm{mCp})$, and their endogenous inhibitor, calpastatin. Calpains represent a highly conserved family of non-lysosomal calcium-dependent cysteine proteases that are composed of a distinct large $(80 \mathrm{kDa})$ catalytic subunit and a common small $30 \mathrm{kDa}$ regulatory subunit (see e.g. Croall and De Martino, 1991). Calpastatin consists of an unique amino-terminal domain $L$ and four tandem repeats of the actual inhibitory domain (1 to 4), each of which contains three motifs termed A, B and C (Maki et al., 1987). Each B motif can specifically inhibit calpain activity.

The intracellular levels of calpains and calpastatin vary between tissues, but calpastatin is generally found at much higher molar levels than calpains (Blomgren, 1999). Both, proteases and inhibitor, are relatively stable with a half-life of up to five days under normal physiological conditions (Zhang et al., 1996). The cytosolic co-localization of calpains and calpastatin under normal conditions indicates that calpain must somehow escape the inhibitory control of calpastatin to become fully activated. In this regard, it has been suggested that subcellular compartmentalization of both molecule species may regulate calpain activity within cells (Lane et al., 1992; GilParrado et al., 2003a).

The wide substrate specificity of calpains underpins their proposed roles in diverse cellular processes, including apoptosis (e.g. Gil-Parrado et al., 2002), cell cycle progression (e.g. Kubbutat et al., 1997), and cell motility (e.g. Carragher et al., 1999). Knock-out mice lacking the gene that encodes the calpain small regulatory subunit die at around 10 days post-conception and exhibit defects in vascular development, suggesting a role for calpain in endothelial cell proliferation, migration or survival. Moreover, fibroblasts derived from these knock-out embryos exhibit impaired cell migration and disruption of the actin cytoskeleton (Dourdin et al., 2001).

Migrating cells use both adhesion receptors (e.g. integrins) and proteolytic enzymes to regulate their interaction with and response to the ECM. Cooperation between integrins and proteases exists at several levels: integrin signaling induces proteases, proteases co-localize with integrins, and proteases regulate the interface between integrins and the intracellular cytoskeleton. Two different mechanisms have been postulated to explain the role played by calpains in cell migration: (i) $\mu \mathrm{Cp}$ activated by 
integrins degrades members of the Rho family of GTP ases, such as Rac and RhoA, which are themselves activated by $\beta 3$-integrins to mediate focal cell adhesion (Bialkowska et al., 2000), and (ii) epidermal growth factor receptor signaling via the ERK/MAPK pathway activates $\mathrm{mCp}$, which induces the proteolytic abrogation of cell adhesion (Glading et al., 2000).

Besides calpains other protease systems, such as matrix metalloproteinases (MMPs) and the urokinase/urokinase receptor (UPAR)/plasmin system, are intimately connected to the integrins and ECM during the process of cell migration. Regulation of MMP expression due to cell-ECM contacts has been reported, and in particular diverse integrins were shown to mediate the expression of the primary matrix degrading proteinases, MMP-9 and MMP-2 (Huhtala et al., 1995). Tumor cell migration through the ECM requires the cooperation of cell adhesion and local proteolysis of ECM components such as basement membranes, collagens, fibronectin and laminin. MMPs are responsible for ECM breakdown under both normal and pathological conditions (reviewed in Itoh and Nagase, 2002). Secretion of MMPs, predominantly of MMP-2 and MMP-9, has been demonstrated in various cellular systems to correlate with the capacity of tumor cells for invasion and metastasis (Stetler-Stevenson et al., 1993).

Although MMPs and the uPA system seem to play the major role in tumor development and invasion, recent results from various studies also point to the relevance of calpain within these processes. For instance, increased calpain activity has been detected in breast cancer tissues (Shiba et al., 1996), and in human renal cell carcinomas significantly higher levels of $\mu \mathrm{Cp}$ expression were found in tumors metastazing to peripheral lymph nodes compared to tumors that have not metastasized (Braun et al., 1999). Interestingly, calpain-mediated proteolysis of the tumor suppressor protein, neurofibromatosis type 2 , is associated with the development of schwannomas and meningiomas (Kimura et al., 2000). Finally, elevated calpain activity in chronic lymphocytic leukemic cells (Witkowski et al., 2002) and involvement of calpains in differentiation of leukemic cells have been reported as well (Deshpande et al., 1995). However, it is not clear how the calpain/calpastatin system is regulated in leukemic cells at diverse stages of differentiation.

In view of the fact that calpain is required for MMP-2 and UPA-expression in SV40 large T-antigen-immortalized cells (Postovit et al., 2002), and that the gelatinases MMP-2 and MMP-9 are highly expressed in leukemic cells (Ries et al., 1999), we focused on a potential interaction between the calpain/calpastatin system and these two gelatinases during leukemic cell invasion. Furthermore, we addressed whether this interaction depends on the cellular differentiation stages, i.e. monocytic, macrophage- or granulocyte-like stages.

To address these issues we cultivated the human monocytic cell line THP-1 under serum-free conditions in RPMI 1640 medium supplemented with 1\% Nutridoma

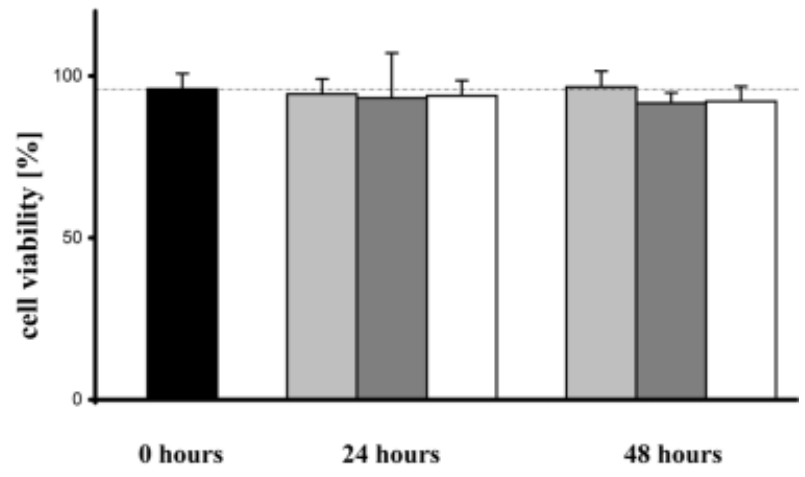

$\square$ Nutridoma $\square$ Nutridoma + PMA $\square$ Nutridoma + DMSO

Fig. 1 Effect of PMA and DMSO on the Viability of Leukemic THP-1 Cells.

Cell viability was assessed by flow cytometry, simultaneously monitoring FITC-labeled annexin $\mathrm{V}$ binding and propidium iodide (PI) uptake. THP-1 (DSMZ \# ACC 16) cells $\left(5 \times 10^{6}\right)$ were treated with PMA or DMSO to induce macrophage- or granulocyte-like differentiation, respectively. Routine cell culture was performed in RPMI 1640 medium (PAA, Linz, Austria) supplemented with $10 \%$ fetal calf serum (PAA) and $1 \%$ glutamine solution (Gibco$\mathrm{BRL}$, Paisley, $\mathrm{UK}$ ) at $37^{\circ} \mathrm{C}$ in a humidified $5 \% \mathrm{CO}_{2}$ incubator. Cell differentiation in serum-free medium supplemented with $1 \% \mathrm{Nu}$ tridoma-SP (Roche, Mannheim, Germany) was stimulated by addition of 80 nм PMA (Sigma, St. Louis, USA) or $1.28 \mu \mathrm{m}$ DMSO (Fluka, Buchs, Switzerland) for 24 or 48 hours. All cell culture materials were purchased from NUNC, (Rochester, USA). After treatment with PMA or DMSO, cells were resuspended in $2 \mathrm{ml}$ of annexin $\mathrm{V}$ binding buffer, and finally analyzed with FITC-annexin $\mathrm{V}$ and $\mathrm{PI}(9: 1)$ for $5 \mathrm{~min}$ at room temperature according to the manufacture's protocol (Roche). Fluorescence of 20000 cells was measured with a flow cytometer (XL-MCL; Coulter, Miami, USA) through 525/20 bandpass filter to monitor annexin-fluorescence-phosphatidylserine binding and through a 620/15 filter to monitor PI uptake. Cell viability (\%) represents the percentage of cells negative for FITC-annexin $\mathrm{V}$ binding and PI related to the total amount of cells. Note that DMSO and PMA do not induce significant cell death during the $48 \mathrm{~h}$ incubation period. The values are given as mean of three independent experiments.

(Roche, Basel). This cell line can be further stimulated to differentiate into a macrophage- or granulocyte-like stage, respectively (Auwerx, 1991; Drexler et al., 1995). For induction of macrophage- (Hubermann and Callaham, 1979) or granulocyte-like (Collins et al., 1978) differentiation cells were treated for 24 or 48 hours with either PMA (80 nM) or DMSO (1.28 $\mu \mathrm{M})$, respectively. Compared to starting conditions neither PMA nor DMSO were cytotoxic throughout a 48 hour study period to a significant extent as assessed by co-staining with annexin $\mathrm{V}$ fluorescein isothiocyanate (FITC) and propidium iodide (PI) (Figure 1). In further experiments, leukemic cells were stimulated to differentiate by pre-incubation with the indicated concentrations of PMA- or DMSO for $24 \mathrm{~h}$. PMAstimulated macrophage differentiation of THP-1 was confirmed by induction of vimentin expression (Cabanas et al., 1990; Figure 2B), as well as by microscopic (Fig- 
$\mathbf{A}$

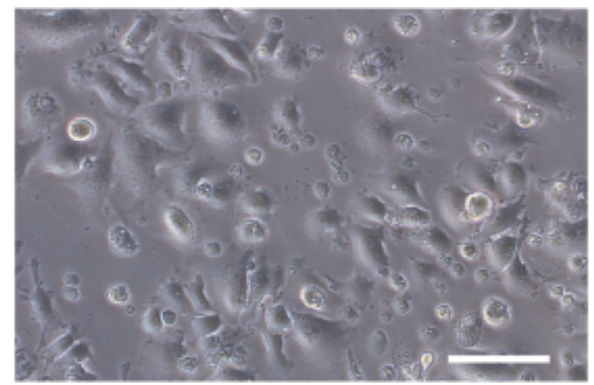

C

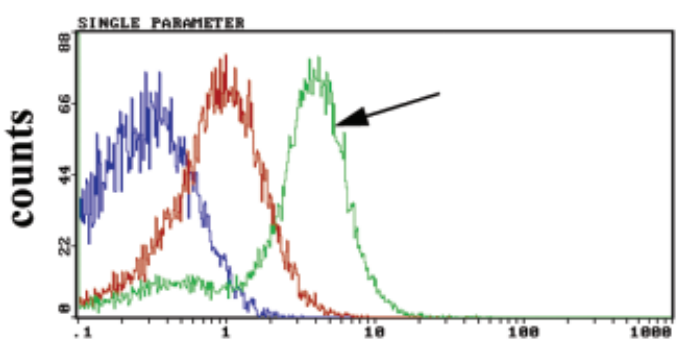

PE Intensity
B

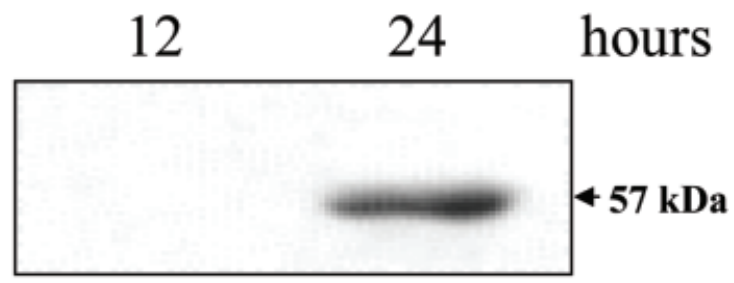

D

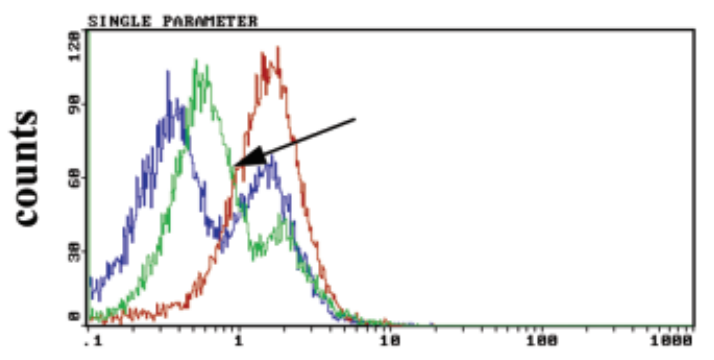

FITC Intensity

Fig. 2 Characterization of Macrophage-Like Differentiation of Leukemic THP-1 Cells.

(A) Adherent becoming cells after PMA-treatment (see legend to Figure 1) for $24 \mathrm{~h}$ (phase contrast). The bar in the panel is equivalent to $30 \mu \mathrm{m}$. (B) Induction of vimentin expression as marker for macrophage-like differentiation. Adherent cells were trypsinized and washed with pre-chilled PBS. For preparation of cytosolic extract, cells were resuspended in freshly prepared lysis buffer (10 mM HEPES, $10 \mathrm{~mm}$ $\mathrm{KCl}, 1.5 \mathrm{~mm} \mathrm{MgCl}_{2}, 1 \mathrm{~mm}$ EDTA, pH 7.5), supplemented with 1\% protease inhibitor cocktail set III (Calbiochem, San Diego, USA), and lysed by four cycles of freezing and thawing. Total protein concentration was determined by the BCA method (Smith et al., 1985). Cytosolic extracts were then mixed with sample buffer, heated for $2-5$ minutes at $95^{\circ} \mathrm{C}$ and electrophoretically resolved on SDS-Tris glycine polyacrylamide (10\%) gels. Finally, samples were transferred to nitrocellulose membranes (Schleicher \& Schuell, Dassel, Germany) and probed with a monoclonal anti-human vimentin antibody (Novocastra, Newcastle, UK). Antibody/protein complexes were detected with anti-mouse horse radish peroxidase (HRP)-linked IgG (New England Biolabs, Beverly,USA), using the SuperSignal ${ }^{\circledR}$ chemiluminescence detection kit (Pierce, Rockford, USA). (C) Increase of the macrophage-specific CD69 [arrow, anti-CD69 phycoerythrin (PE); Caltag, Burlingame, USA] and (D), fading of hematopoietic progenitor marker CD34 (arrow, anti-CD34-FITC; Caltag) were observed using fluorescence-assisted analysis. For this, PMA-stimulated cells were washed and incubated for 30 minutes on ice with the appropriate antibody and subsequently analyzed using a flow cytometer (XL-MCL, Coulter). Blue, isotype control; red, untreated cells; green, treated cells. Results are representative of three replicas.
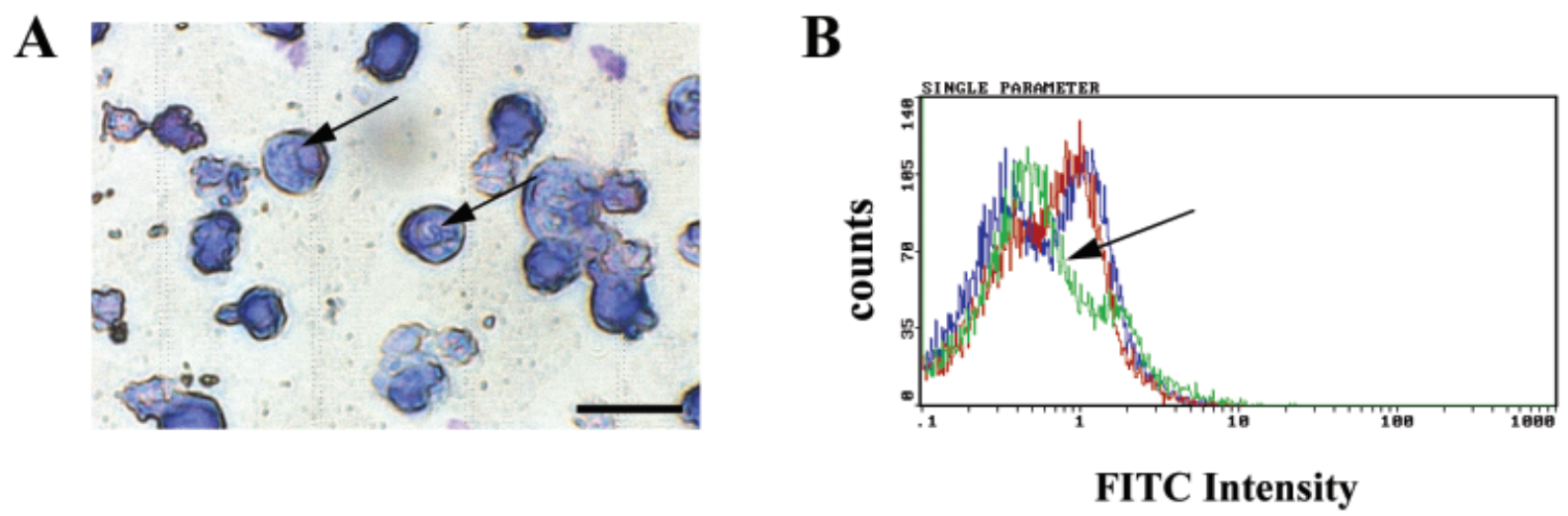

Fig. 3 Characterization of Granulocyte-Like Differentiation of Leukemic THP-1 Cells.

(A) Granulocyte-like differentiation of THP-1 cells after treatment with DMSO for $24 \mathrm{~h}$ (see legend to Figure 1) shown by Wright-Giemsa-staining (arrow). The bar in the panel is equivalent to $30 \mu \mathrm{m}$. (B) Reduction of hematopoietic progenitor CD34 was detected by fluorescence-assisted analysis (arrow, anti-CD34-FITC; Caltag). Blue, isotype control; red, untreated cells; green, treated cells. Results are representative of three replicas. 
ure 2A) and fluorescence-assisted cytometric analysis (Figure 2C-D). We detected an increase in the expression level of the macrophage-specific CD69 (Figure 2C), a differentiation marker of cells becoming adherent, with a simultaneous reduction of the hematopoietic progenitor marker CD34 (Figure 2D). In addition, cells incubated with DMSO were stained with Wright-Giemsa-reagent (Figure 3A), exhibiting granulocyte subcellular components concomitantly with the reduction of both the hematopoietic progenitor marker CD34 (Figure 3B) and of $\alpha$-naphthyl acetate esterase activity (data not shown).

Summarizing the native $(80 \mathrm{kDa})$ and the autolytical product $(76 \mathrm{kDa})$ of the large subunit, calpain protein lev- els in the cytosolic extracts as determined by Western blotting were nearly unchanged after stimulation of the leukemic cell lines with PMA or DMSO (Figure 4A). Further, we did not detect significant differences in hydrolysis of the fluorogenic peptide substrate Suc-LY-amc in cytosolic extracts (Figure 4B, bars 1). This activity was reduced by CP1B (Figure 4B, bars 2), a highly specific calpain inhibitor $\left(K_{\mathrm{i}}\right.$ values: $0.2 \mathrm{~nm}$ for calpain, $6 \mu \mathrm{m}$ for cathepsin L, $\geq 500 \mu \mathrm{m}$ for cathepsin B and caspase 3 ) derived from the $\mathrm{B}$ motif of calpastatin (Gil-Parrado et al., 2003b), indicating that a significant part of the Suc-LYamc hydrolytic activity resulted from calpain. In addition, cytosolic extracts of cells pre-incubated for $24 \mathrm{~h}$ with

A

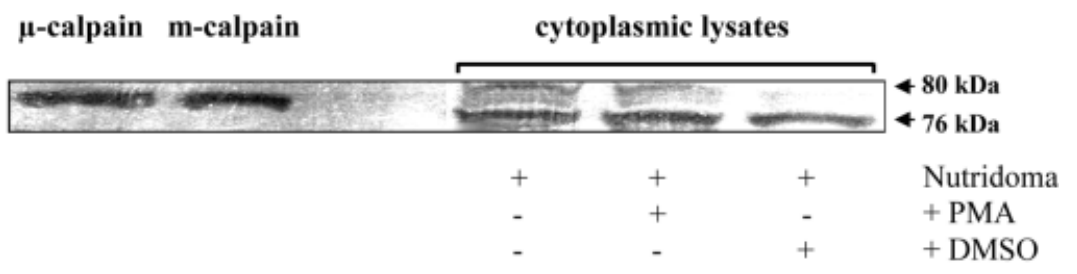

B

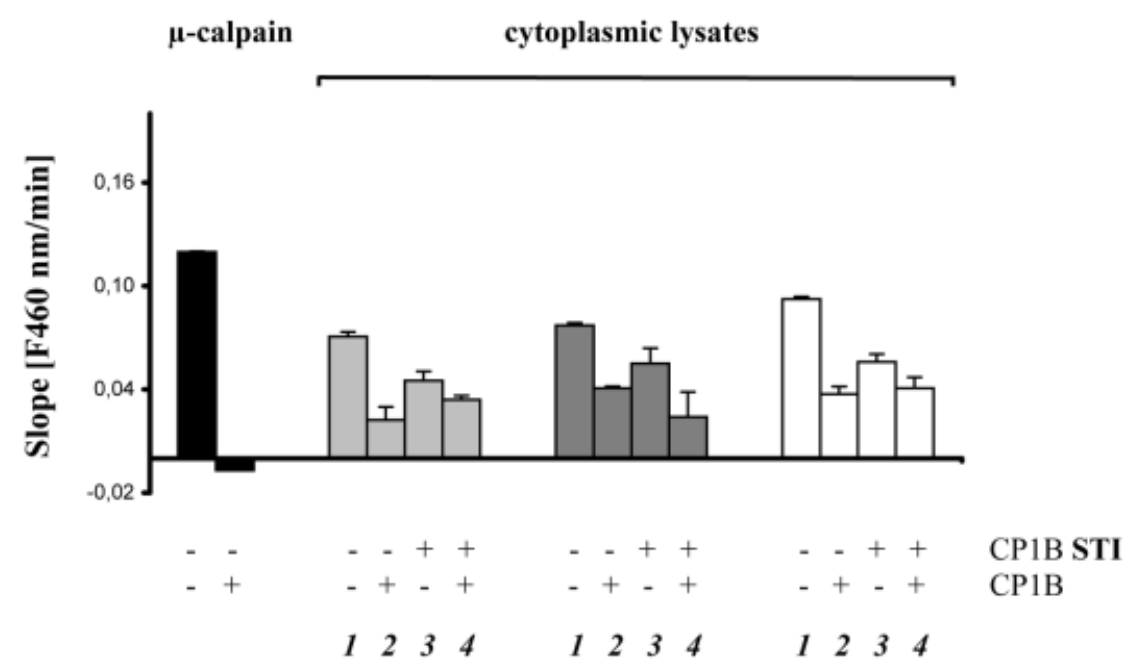

Nutridoma $\square$ Nutridoma + PMA $\square$ Nutridoma + DMSO

Fig. 4 Calpain Expression and Activity in Cytosolic Extracts of THP-1 Cells Cultivated under Basal and Differentiation-Stimulating Conditions.

(A) Western blot analysis of cytosolic extracts (see also legend to Figure 1) for calpain expression in THP-1 cells indicate no significant differences in the expression of the calpain large subunit $(80 \mathrm{kDa}, 76 \mathrm{kDa})$. Cytosolic extracts were electrophoretically separated and transferred to a nitrocellulose membrane as described in Figure 2. The samples were probed against a monoclonal anti-human calpain antibody (RDI, Flanders, USA), recognizing the native $(80 \mathrm{kDa})$ and the autolytic product $(76 \mathrm{kDa})$ of the calpain large subunit as well. (B) Calpain activity in cytosolic extracts $(n=3)$ from cells either pre-incubated or not with CP1B (50 $\mu \mathrm{M}$, CP1B STI) for $24 \mathrm{~h}$ revealed no significant differences between unstimulated and differentiation-stimulated cells (bars 1) as measured by hydrolysis of the fluorogenic peptide substrate Suc-LY-amc. Most of the Suc-LY-amc hydrolysis could be inhibited by pre-incubation with the specific calpain inhibitor CP1B (10 nM, Sigma; bars 2), indicating that calpain is mainly responsible for this activity. Further, pre-incubation of cells with $\mathrm{CP} 1 \mathrm{~B}(50 \mu \mathrm{M})$ for $24 \mathrm{~h}$ markedly reduced the calpain activity since non significantly differences were detected between CP1B-pre-incubated cells before (bars 3 ) and after addition (bars 4) of CP1B (10 nM) during the activity assay. As positive control, purified human $\mu \mathrm{Cp}(5 \mathrm{nM})$ isolated from erythrocytes was used. The activity assay contained $100 \mathrm{~mm} \mathrm{DTT,} 20 \mathrm{~mm} \mathrm{CaCl}, 25 \mathrm{~mm}$ Suc-LY-amc and appropriate amounts of sample ( $5 \mu \mathrm{g}$ cytosolic extracts). All experiments were performed in triplicate. 
A

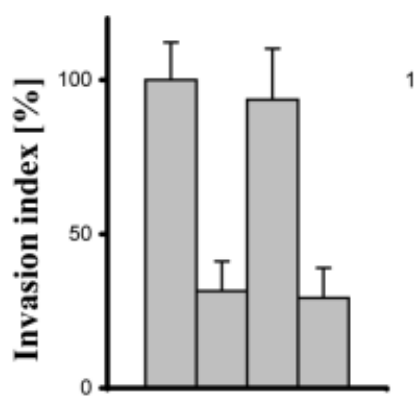

$-+-+$

$-\quad++$

$\begin{array}{llll}1 & 2 & 3 & 4\end{array}$

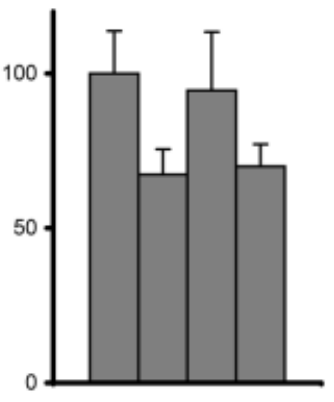

$-+-+$

$-\quad++$

$\begin{array}{llll}1 & 2 & 3 & 4\end{array}$

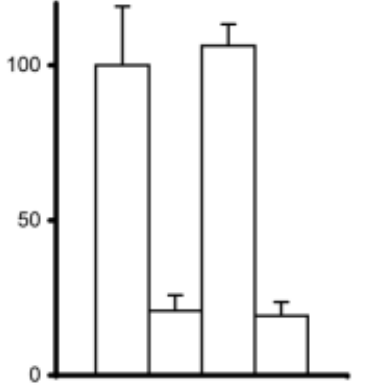

-+-+ CP1B STI

-+++ CP1B INV

$\begin{array}{llll}1 & 2 & 3 & 4\end{array}$

$\square$ Nutridoma $\square$ Nutridoma + PMA $\square$ Nutridoma + DMSO

B

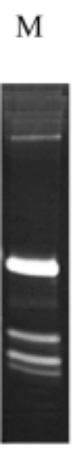

Nutridoma + PMA

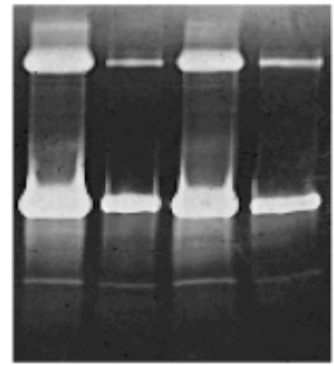

Nutridoma + DMSO

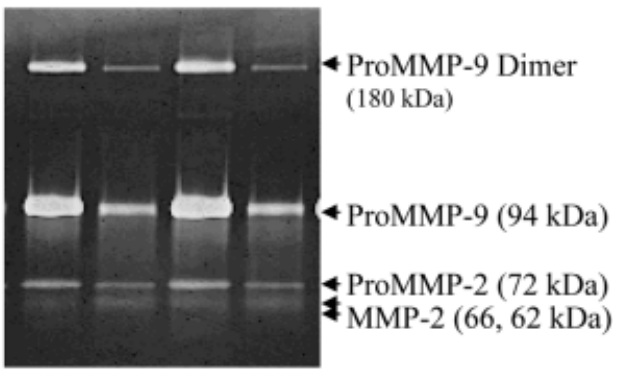

$\begin{array}{cccccccccccc}- & + & - & + & - & + & - & + & - & + & - & + \\ - & - & + & + & - & - & + & + & - & - & + & + \\ & & & & & \text { CP1B STI INV } \\ 1 & 2 & 3 & 4 & 1 & 2 & 3 & 4 & 1 & 2 & 3 & 4\end{array}$

Fig. 5 Reduction of ECM Invasion and Secretion of MMP-2 and MMP-9 by Pre-Incubation of THP-1 Cells with the Calpain Inhibitor CP1B.

(A) The cell invasion assay was performed as previously described (Zang et al., 2000). THP-1 cells either untreated or stimulated to differentiate with PMA and DMSO, were pre-incubated or not with CP1B (50 $\mu \mathrm{M})$ for $24 \mathrm{~h}$ (CP1B STI). The cells ( $\left.1 \times 10^{5}\right)$ were washed and then plated on a $6 \mu \mathrm{m}$ pore transwell insert (Costar, Cambridge, USA) coated with $20 \mu \mathrm{g}$ Matrigel (mouse ECM; Becton Dickinson, Franklin Lakes, USA). The upper and lower compartments of the transwell chamber contained RPMI medium supplemented with $1 \%$ Nutridoma in the presence or absence of CP1B (50 $\mathrm{\mu M}$ ) (CP1B INV). The lower compartment contained $1 \%$ fetal calf serum to induce chemotactic cell migration. After $24 \mathrm{~h}$ of incubation at $37^{\circ} \mathrm{C}$ and $5 \% \mathrm{CO}_{2}$, cells that had transmigrated either into the lower compartment or remained at the filter were quantified using a Neubauer chamber (cell number) or a fluorescence reader ( $F_{635 n \mathrm{~m}}$; Tecan, Maennedorf, Switzerland), respectively. Remarkably, cells cultivated in Nutridoma or treated with DMSO were only found in the lower compartment, in contrast to cells treated with PMA that remained at the filter after transmigration. Briefly, transmigrated cells that remained at the filter were rinsed in phosphate-buffered saline (PBS) and immersed for 10 minutes in $3.7 \%$ freshly prepared formaldehyde. Thereafter, these cells were permeabilized for 2 minutes with $0.2 \%$ Triton X-100. Finally, cells were stained with $20 \mu \mathrm{g} / \mathrm{ml} \mathrm{PI} \mathrm{(DNA-label)} \mathrm{for} 30$ minutes before fluorescence readings. The relative migration (invasion index) was calculated by setting the number of migrated cells without $\mathrm{CP} 1 \mathrm{~B}$ addition in each treatment [Nutridoma (monocytic): $2354 \pm 352$ cells $+0 \mathrm{~F}_{635 \mathrm{~nm}}$; PMA-treated cells (macrophage-like): 0 cells $+368 \pm 50 \mathrm{~F}_{635 \mathrm{~nm}}$; DMSOtreated cells (granulocyte-like): $7020 \pm 1404$ cells $+0 F_{635 \mathrm{~nm}}$ ] as $100 \%$. Note that pre-incubation of the cells with CP1B for $24 \mathrm{~h}$ significantly reduced the ECM invasiveness of THP-1 cells. Cell viability as assessed by the trypan blue-exclusion dye test (Sigma) amounted to $96 \pm 5 \%$. The values are given as mean of four independent experiments. (B) Analysis of the secreted proenzyme forms of MMP-2 and MMP-9 was performed by zymography using minigels containing $0.1 \%$ gelatin according to the manufacture's protocol (Invitrogen, Carlsbad, USA). Aliquots of conditioned media ( $8 \mu \mathrm{g}$ total protein) collected from the upper compartment of the invasion chamber were subjected to zymography. Remarkably, secretion of MMP-9 (and to a lesser degree of MMP-2) detected by gel scanning of the lysis area (Jaroslava et al., 1999) was significantly diminished in cells that had been pre-incubated with CP1B for $24 \mathrm{~h}$. In contrast, addition of CP1B only during the invasion process did not reduce transmigration capacity (A) nor MMP release (B). As control for MMP-2 and MMP-9 release, conditioned medium from HT 1080 cells was used (M) (Stanton et al., 1998). 
cell-permeable CP1B were also analyzed for Suc-LY-amc hydrolysis. This treatment reduced significantly the SucLY-amc hydrolytic activity (Figure 4B, bars 3), again suggesting the inhibition of calpain activity throughout the incubation period. Finally, and consistent with these results, exogenous addition of $\mathrm{CP} 1 \mathrm{~B}$ to the latter extracts during the activity assay did only slightly further diminish Suc-LY-amc hydrolytic activity (Figure 4B, bars 4). Thus, these results conclusively confirm that pre-incubation with CP1B for $24 \mathrm{~h}$ reduces significantly calpastatin-inhibitable Suc-LY-amc hydrolysis, and therefore, calpain activity.

Since several calpain substrates are components of focal adhesion complexes whose remodeling is required for cellular migration, we studied the influence of calpain activity on the invasiveness of THP-1 cells using a Matrigel-based (ECM) transwell invasion assay in the presence or absence of CP1B. Before applying the cells in the invasion assay, basal and differentiation-stimulating cultivation of THP-1 cells was performed in the presence and absence of the calpain inhibitor as outlined above. The invasion index was defined as relative migration by setting the number of untreated cells that had migrated to the lower compartment as $100 \%$. Remarkably, the invasion index of both differentiation-stimulated and untreated cells was significantly reduced after pre-incubation with CP1B for $24 \mathrm{~h}$ (Figure 5A).

To evaluate a possible interaction between the calpain/calpastatin system and MMPs, culture supernatants of THP-1 cells either pre-incubated or not with CP1B during (i) differentiation, (ii) invasion or (iii) differentiation and invasion were analyzed for secreted MMP-2 and MMP-9 using gelatin-incorporated SDS polyacrylamide gels. This zymographic analysis of THP-1 culture supernatants showed a constitutive secretion of MMP-2 and MMP-9 in their proenzyme form with apparent molecular masses of 72 and $94 \mathrm{kDa}$, respectively. An additional band at $180 \mathrm{kDa}$ appears to represent the MMP-9 dimer as observed under non-reducing condition of zymography gels (Olson et al., 2000) (Figure 5B). Stimulation of the cells with PMA or DMSO significantly augmented the release of MMP-9 but not of MMP-2, which is in accord with previous findings in these cells (Van Ranst et al., 1991). Treatment of the cells for 24 hours with CP1B during cultivation under basal conditions as well as during stimulation with PMA or DMSO induced a prominent down-regulation of MMP-9 and to a lesser degree also of MMP-2 secretion (Figure $5 \mathrm{~B}$ ).

To rule out that MMP-2 and - 9 secretion as well as reduced invasiveness were results of PMA- or DMSO-induced cell death, cell viability was monitored by cell staining with trypan blue after transmigration, exhibiting no relevant cell death (data not shown). On the other hand, there is ample evidence suggesting that $\mathrm{CP} 1 \mathrm{~B}$ is not cytotoxic, e.g. CP1B (50 $\mu \mathrm{M})$ prevents ionomycin-induced apoptosis of LCLC $103 \mathrm{H}$ and COS 7 cells (Gil-Parrado et al., 2002). Further indirect evidence for the noncytotoxicity of CP1B is provided by the observation that addition of $\mathrm{CP} 1 \mathrm{~B}$ during the transmigration assay (Figure 5, CP1B INV) for 24 hours did not affect invasion (Figure 5, bars 3) or MMP-expression (Figure 5, lanes 3).

Since addition of CP1B only during the invasion had no
MMP-2

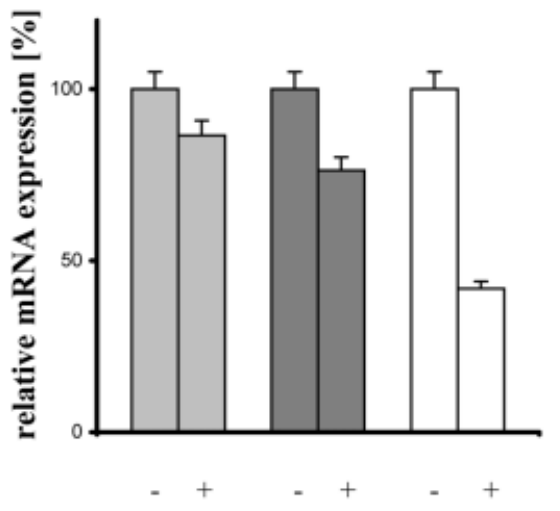

MMP-9

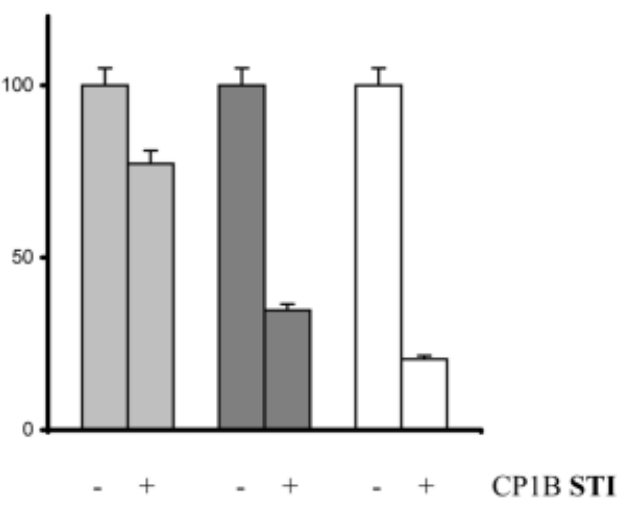

Fig. 6 Reduction of MMP-2 and MMP-9 mRNA Expression by Pre-Incubation of THP-1 Cells with CP1B.

THP-1 cells, either unstimulated (Nutridoma) or treated with PMA or DMSO, were cultivated for $24 \mathrm{~h}$ without or with CP1B (50 $\mu$ M). Thereafter, total RNA was isolated using the RNeasy ${ }^{\circledR}$ Kit (Qiagen, Hilden, Germany) according to the manufacturer's protocol. The isolated RNA was reverse transcribed in cDNA with the First Strand cDNA Synthesis Kit (Roche). Primers for RT-PCR were purchased from Search LC (Heidelberg, Germany). Quantification of mRNA levels was carried out by automated real-time RT-PCR (LightCycler ${ }^{\mathrm{TM}}$, Roche). mRNA levels of MMP-2 and MMP-9 were normalized to that of the house-keeping gene GAPDH. The relative mRNA expression was calculated by setting the normalized mRNA levels of cells (unstimulated and stimulated with PMA or DMSO) without inhibitor treatment as $100 \%$. Note that reduced mRNA expression of MMP-2 and especially of MMP-9 correlates with the diminished secretion of these proteinases during the ECM invasion by THP-1 cells (see Figure $5 B$ ). 
effect on the release of these two MMPs, we hypothesized that the calpain/calpastatin system might regulate primarily the expression of MMPs rather than their secretion. Therefore, we quantified the mRNA expression levels of MMP-2 and MMP-9 from unstimulated and differentiation-stimulated cells cultivated for $24 \mathrm{~h}$ in the presence or absence of CP1B (Figure 6). Indeed, a significant reduction of the gelatinase mRNA levels from cells pre-incubated with $\mathrm{CP} 1 \mathrm{~B}$ was found using real-time quantitative PCR. Noteworthy, the CP1B-mediated decrease was observed in unstimulated leukemic cells as well as in their macrophage- and granulocyte-like stages. The stronger reduction of MMP-9 mRNA levels compared to those of MMP-2 correlated with both fewer proenzyme release of MMP-9 than of MMP-2 as shown by zymography (Figure $5 \mathrm{~B}$ ) and reduced invasiveness (Figure 5A). Since invasion requires extracellularly active proteases for breakdown of the ECM, one can expect that the amount of released proMMPs correlates with their activation during the invasion process (Nagase and Woessner, 1999).

Although calpains are localized mostly intracellularly, several reports indicated the presence of extracellular mCp on collagen fibrils (Badalamante et al., 1987), in endoneural collagen fibrils and the basal laminae of Schwann cells (Mata et al., 1991), around the cartilagenous matrix (Shimizu et al., 1991), and in extracellular fibrous tissues, calluses and perivascular areas (Nakagawa et al., 1994). To evaluate whether extracellular calpain might have been involved in the invasion process, we analyzed the culture supernatants of the upper compartment of the invasion chamber for the presence of secreted calpain. However, using an ELISA that had been optimized for calpain detection in conditioned medium, we could not detect any increase in the calpain release during transmigration by these leukemic cells independently on the differentiation stage (data not shown). Nevertheless, we would like to emphasize that our results do not exclude the possibility that activated calpain bound to the cell membrane (Gil-Parrado et al., 2003a) of migrating cells might have contributed to ECM degradation during invasion.

In summary, we have demonstrated that the specific calpain inhibitor, CP1B, reduces ECM invasion as well as mRNA expression of MMP-9 and MMP-2 and thus also the secretion of these proteinases by leukemic (THP-1) cells independently of their differentiation stages. This is the first report showing that the calpain/calpastatin system mediates MMP-mRNA expression of leukemic (THP-1) cells and as a consequence their invasiveness. Our evidences extend recent reports suggesting the involvement of calpain activity on the regulation of MMP-2 during SV40 large T-antigen-mediated immortalization of fibroblasts lacking the gene for the small subunit of calpain (Postovit et al., 2002). How the calpain/calpastatin system regulates the invasiveness of non-transformed hematopoietic cells (e.g., monocytes) as well as of cells with different malignancies remains to be investigated. In addition, the precise mechanism(s) by which calpain influences the expression of these MMPs still deserves investigation. Interestingly, calpain has been reported to be involved in the ERK/MAPK signaling pathway (Glading et al., 2000), which is also known to modulate MMP9 mRNA expression (Westermarck and Kähäri, 1999). Understanding the mechanism of MMP regulation by the calpain/calpastatin system may lead to the development of novel (antiproteolytic) therapeutic approaches against leukemic diseases.

\section{Acknowledgments}

We are grateful to Ducisa Gabrijelcic-Geiger for providing the calpain-ELISA setup. We also thank Pablo Fuentes Prior for critical review of the manuscript. This work was supported by the Deutsche Forschungsgemeinschaft (Sonderforschungsbereich 469 of the LMU München, grants A3 and B1).

\section{References}

Auwerx, J. (1991). The human leukaemia cell line, THP-1: a multifacetted model for the study of monocyte-macrophage differentiation. Experientia 47, 22-31.

Badalamente, M. A., Hurst L. C., and Stracher, A. (1987). Localization and inhibition of calcium-activated neutral protease (CANP) in primate skeletal muscle and peripheral nerve. Exp. Neurol. 98, 357-369.

Bialkowska, K., Kulkarni, S., Du, X., Goll, D. E., Saido, T. C., and Fox, J. E. (2000). Evidence that $\beta 3$-integrin-induced Rac activation involves the calpain-dependent formation of integrin clusters that are distinct from the focal complexes and focal adhesions that form as Rac and RhoA become active. J. Cell Biol. 151, 685-695.

Blomgren, K. (1999). Calpastatin is upregulated and acts as a suicide substrate to calpains in neonatal rat hypoxia-ischemia. Ann. NY Acad. Sci. 890, 270-271.

Braun, C., Engel, M., Seifert, M., Theisinger, B., Seitz, G., Zang, K. D., and Welter, C. (1999). Expression of calpain I messenger RNA in human renal cell carcinoma: correlation with lymph node metastasis and histological type. Int. J. Cancer. 84, 6-9.

Cabanas, C., Sanchez-Madrid, F., Aller, P., Yague, E., and Bernabeu, C. (1990). Phorbol esters induce differentiation of U937 human promonocytic cells in the absence of LFA1/ICAM-1-mediated intercellular adhesion. Eur. J. Biochem. 191, 599-604.

Carragher, N. O., Levkau, B., Ross, R., and Raines, E. W. (1999). Degraded collagen fragments promote rapid disassembly of smooth muscle focal adhesions that correlates with cleavage of pp125 FAK, paxillin and talin. J. Cell Biol. 147, 619-629.

Collins, S. J., Bonder, A., Ting, R. and Gallo, R. C. (1978). Terminal differentiation of human promyelocytic leukaemia cells (HL-60) by dimethyl sulfoxide and other polar compounds. Proc. Natl. Acad. Sci. USA 75, 2458-2462.

Croall, D. E., and DeMartino, G. N. (1991). Calcium-activated neutral protease (calpain) system: structure, function, and regulation. Physiol. Rev. 71, 813-814.

Deshpande, R. V., Goust, J. M., Chakrabarti, A. K., Barbosa, E., Hogan, E. L., and Banik, N. L. (1995). Calpain expression in lymphoid cells. Increased mRNA and protein levels after cell activation. J. Biol. Chem. 270, 2497-2505.

Dourdin, N., Bhatt, A. K., Dutt, P., Greer, P. A., Arthur, J. S., Elce, 
J. S., and Huttenlocher, A. (2001). Reduced cell migration and disruption of the actin cytoskeleton in calpain-deficient embryonic fibroblasts. J. Biol. Chem. 276, 48382-48388.

Drexler, H. G., Quentmeier, H., MacLeod, R. A., Uphoff, C. C., and Hu, Z. B. (1995). Leukaemia cell lines: in vitro models for the study of acute promyelocytic leukaemia. Leuk. Res. 19, 681-691.

Glading, A., Chang, P., Lauffenburger, D. A., and Wells, A. (2000). Epidermal growth factor receptor activation of calpain is required for fibroblast motility and occurs via an ERK/MAP kinase signaling pathway. J. Biol. Chem. 275, 2390-2398.

Gil-Parrado, S., Fernández-Montalván, A., Assfalg-Machleidt, I., Popp, O., Bestvater, F., Holloschi, A., Knoch, T. A., Auerswald, E. A., Welsh, K., Reed, J. C. et al. (2002). Ionomycinactivated calpain triggers apoptosis. J. Biol. Chem. 277, 27217-27226

Gil-Parrado, S., Popp, O., Knoch, T. A., Zahler, S., Bestvater, F., Felgentrager, M., Holloschi, A., Fernandez-Montalvan, A., Auerswald, E. A., Fritz, H., Fuentes-Prior, P., Machleidt, W., and Spiess, E. (2003a). Subcellular localization and in vivo subunit interactions of ubiquitous $\mu$-calpain. J. Biol. Chem. 278, $16336-16346$

Gil-Parrado, S., Machleidt, I.A., Fiorino, F., Deluca, D., Pfeiler, D., Schaschke, N., Moroder, L., and Machleidt, W. (2003b). Calpastatin exon 1B-derived peptide, a selective inhibitor of calpain: enhancing cell permeability by conjugation with penetratin. Biol. Chem. 384, 395-402.

Huhtala, P., Humphries, M. J., McCarthy, J. B., Tremble, P. M., Werb, Z., and Damsky, C. H. (1995). Cooperative signaling by $\alpha 5 \beta 1$ - and $\alpha 4 \beta 1$-integrins regulates metalloproteinase gene expression in fibroblasts adhering to fibronectin. J. Cell Biol. 129, $867-879$.

Hubermann, E. and Callaham, M. F. (1979). Induction of terminal differentiation in human promyelocytic leukaemia cells by tumor-promoting agents. Proc. Natl. Acad. Sci. USA 76, $1293-$ 1297.

Itoh, Y. and Nagase, H. (2002). Matrix metalloproteinases in cancer. Essays Biochem. 38, 21-36.

Jaroslava, L., Dauchot, P., Perrot, J. L., Cambazard, F., Frey, J. and Chamson, A. (1999). Quantitative zymography of matrix metalloproteinases by measuring hydroxyproline: application to gelatinases A and B. Electrophoresis 20, 2824-2829.

Kimura, Y., Saya, H., and Nakao, M. (2000). Calpain-dependent proteolysis of NF2 protein: involvement in schwannomas and meningiomas. Neuropathology 20, 153-160.

Kubbutat, M. H., and Vousden, K. H. (1997). Proteolytic cleavage of human p53 by calpain: a potential regulator of protein stability. Mol. Cell. Biol. 17, 460-468.

Lane, R. D., Allan, D. M., and Mellgren, R. L. (1992). A comparison of the intracellular distribution of $\mu$-calpain, m-calpain, and calpastatin in proliferating human A431 cells. Exp. Cell Res. 203, 5-16.

Maki, M., Takano, E., Mori, H., Sato A., Murachi, T., and Hatanaka, M. (1987). All four internally repetitive domains of pig calpastatin possess inhibitory activities against calpains I and II. FEBS Lett. 223, $174-180$

Mata, M., Supina, N., and Fink, D. J. (1991). Calpain II in rat peripheral nerve. Brain Res. 564, 328-331.

Nagase, H., and Woessner Jr., J. F. (1999). Matrix metalloproteinases. J. Biol. Chem. 274, 21491-21494.

Nakagawa, Y., Shimizu, K., Hamamoto, T., Suzuki, K., Ueda, M., and Yamamuro, T. (1994). Calcium-dependent neutral proteinase (calpain) in fracture healing in rats. J. Orthop. Res. 12, $58-69$.
Olson, M. W., Bernardo, M. M., Pietila, M., Gervasi, D. C., Toth, M., Kotra, L. P., Massova, I., Mobashery, S., and Fridman, R. (2000). Characterization of the monomeric and dimeric forms of latent and active matrix metalloproteinase-9. Differential rates for activation by stromelysin 1. J. Biol. Chem. 275, $2661-2668$.

Postovit, L. M., Dutt, P., Dourdin, N., Park, M., Greer, P. A., Graham, C. H., and Elce, J. S. (2002). Calpain is required for MMP-2 and u-PA expression in SV40 large T-antigen-immortalized cells. Biochem. Biophys. Res. Commun. 297, 294301.

Ries, C., Loher, F., Ismair, M.G., Zang, C., and Petrides, P.A. (1999). Matrix metalloproteinase production by bone marrow mononuclear cells from normal individuals and patients with acute and chronic myeloid leukemia or myelodysplastic syndromes. Clin. Cancer Res. 5, 1115-1124.

Shiba, E., Kim, S., Fujitani, M., Kambayashi, J. I., Kawamura, I., Tsujimoto, S., Shimomura, K., Tanji, Y., Taguchi, T., Kimoto Y., Izukura, M., and Takai, S. I. (1996). Possible involvement of calpain in the growth of estrogen receptor positive breast cancer cells. Anticancer Res. 16, 773-777.

Shimizu, K., Hamamoto, T., Hamakubo, T., Lee, W. J., Suzuki, K., Nakagawa, Y., Murachi, T., and Yamamuro, T. (1991). Immunohistochemical and biochemical demonstration of calcium-dependent cysteine proteinase (calpain) in calcifying cartilage of rats. J. Orthop. Res. 9, 26-36.

Smith, P. K., Krohn, R. I., Hermanson, G. T., Mallia, A. K., Gartner, F. H., Provenzano, M. D., Fujimoto, E. K., Goeke, N. M., Olson, B. J., and Klenk, D. C. (1985). Measurement of protein using bicinchoninic acid. Anal. Biochem. 150, 76-85.

Stanton, H., Gavrilovic, J., Atkinson, S. J., d'Ortho, M., Yamada, K. M., Zardi, L., and Murphy, G. (1998). The activation of proMMP-2 (gelatinase A) by HT1080 fibrosarcoma cells is promoted by culture on a fibronectin substrate and is concomitant with an increase in processing of MT1-MMP (MMP14) to a $45 \mathrm{kDa}$ form. J. Cell Sci. 111, 2789-2798.

Stetler-Stevenson, W. G., Liotta, L. A., and Kleiner Jr., D. E. (1993). Extracellular matrix 6: role of matrix metalloproteinases in tumor invasion and metastasis. FASEB J. 7, 1434-1441.

Van Ranst, M., Norga, K., Masure, S., Proost, ., Vanderkerckhove, F., Auxwer, J., Van Damme, J., and Opdenakkerm, G. (1991). The cytokine-protease connection: identification of a 96-kDa THP-1 gelatinase and regulation by interleukin-1 and cytokine inducers. Cytokine 3, 231-239.

Westermarck, J. and Kähäri V. M. (1999). Regulation of matrix metalloproteinase expression in tumor invasion. FASEB J. 13, $781-792$.

Witkowski, J. M., Zmuda-Trzebiatowska, E., Swiercz, J. M., Cichorek, M., Ciepluch, H., Lewandowski, K., Bryl, E., and Hellmann, A. (2002). Modulation of the activity of calcium-activated neutral proteases (calpains) in chronic lymphocytic leukaemia (B-CLL) cells. Blood 100, 1802-1809.

Zhang, W., Lane, R. D., and Mellgren, R. L. (1996). The major calpain isozymes are long-lived proteins. Design of an antisense strategy for calpain depletion in cultured cells. J. Biol. Chem. $271,18825-18830$.

Zang, C., Liu, H., Ries, C., Ismair, M. G., and Petrides, P. E. (2000). Enhanced migration of the acute promyelocytic leukaemia cell line NB4 under in vitro conditions during shortterm all-trans-retinoic acid treatment. J. Cancer Res. Clin. Oncol. 126, 33-40.

Received March 24, 2003; accepted April 22, 2003 